\title{
The effects of recombinant insulin-like growth factor I administration on growth hormone levels and insulin requirements in adolescents with Type 1 (insulin-dependent) diabetes mellitus
}

\author{
T.D.Cheetham ${ }^{1}$, J.Jones ${ }^{2}$, A.M.Taylor ${ }^{2}$, J.Holly ${ }^{3}$,D.R.Matthews ${ }^{4}$, D.B. Dunger ${ }^{1}$ \\ ${ }^{1}$ Department of Paediatrics, John Radcliffe Hospital, Oxford, UK \\ ${ }^{2}$ Department of Growth and Development, Institute of Child Health, University of London, London, UK \\ ${ }^{3}$ Department of Chemical Endocrinology, St Bartholomew's Hospital, London, UK \\ ${ }^{4}$ Diabetes Research Laboratories, Radcliffe Infirmary, Oxford, UK
}

\begin{abstract}
Summary. Type 1 (insulin-dependent) diabetes mellitus in adolescence is associated with reduced levels of insulin-like growth factor I, elevated growth hormone concentrations and insulin resistance. In order to determine whether restoring insulin-like growth factor I levels to normal might lead to a reduction in growth hormone levels and insulin requirements, we undertook a double-blind placebo controlled study of a single s. c. dose of recombinant insulin-like growth factor $\mathrm{I}(40 \mu \mathrm{g} / \mathrm{kg}$ body weight $)$ in nine late pubertal subjects with Type 1 diabetes. After administration of placebo or insulin-like growth factor I at 18.00 hours, a variable rate insulin infusion was used to maintain euglycaemia overnight. Plasma insulin-like growth factor I, growth hormone, free insulin, and intermediate metabolite concentrations were monitored throughout the study. Recombinant insulin-like growth factor I led to a rise in plasma concentrations which reached a peak at $5.5 \mathrm{~h}(413.1 \pm 28.2 \mathrm{ng} / \mathrm{ml}$, mean \pm SEM $)$.
\end{abstract}

Mean growth hormone levels between 20.00 and 08.00 hours were significantly reduced after recombinant insulin-like growth factor I (19.4 \pm 4.0 compared with $33.6 \pm 5.8 \mathrm{mU} / \mathrm{l}$; $p=0.01$ ), as were the insulin requirements for euglycaemia $\left(0.25 \pm 0.02\right.$ compared with $0.31 \pm 0.04 \mathrm{mU} \cdot \mathrm{kg}^{-1} \cdot \mathrm{min}^{-1}$; $p=0.03$ ). Plasma free insulin levels were lower after recombinant insulin-like growth factor I administration $(31.9 \pm 2.7$ compared with $67.9 \pm 16.0 \mathrm{mU} / \mathrm{l} ; p=0.001)$ but no significant differences in ketone or lactate levels were detected. Recombinant insulin-like growth factor I in a s.c. dose of $40 \mu \mathrm{g} / \mathrm{kg}$ body weight leads to a significant reduction in overnight growth hormone levels and insulin requirements in adolescents with Type 1 diabetes.

Key words: Type 1 (insulin-dependent) diabetes mellitus, insulin requirements, insulin-like growth factor I, growth hormone, adolescence.
Adolescents with Type 1 (insulin-dependent) diabetes mellitus have elevated peak and baseline growth hormone (GH) levels compared with control subjects at all stages of puberty $[1,2]$. Several studies have shown an association between changes in peak GH concentrations and insulin resistance with an effect ranging between 2 to $7 \mathrm{~h}$ after peak GH levels [3, 4]. This corresponds to the dawn phenomenon of increasing insulin requirements overnight if euglycaemia is to be maintained [5]. A further consequence of the elevated GH levels is enhanced ketogenesis with abnormally high B-hydroxybutyrate and acetoacetate levels [6]. Finally, the elevated GH levels have been implicated in the development of the microvascular complications of diabetes. The anabolic and growth promoting effects of GH are largely mediated by insulin-like growth factor I (IGF-I) and it has been proposed that the high GH levels seen in adolescents with Type 1 diabetes are partly due to increased pituitary secretion as a response to feedback drive from reduced or low-normal levels of IGF-I and reduced IGF bioactivity $[7,8]$.
In order to determine whether physiological doses of recombinant human IGF-I (rbIGF-I) would cause a reduction in GH levels and thus reduce the dawn rise in insulin requirements in adolescents with Type 1 diabetes, we undertook a placebo-controlled double-blind trial of rhIGF-I administered in a single s. c. dose of $40 \mu \mathrm{g} / \mathrm{kg}$ body weight.

\section{Subjects, materials and methods}

The subjects were nine adolescents with Type 1 diabetes (five female and four male), median age 16 years (range 14-18 years) who were in late puberty (Tanner stage 4 or 5 ). Their duration of diabetes was greater than 3 years and stimulated C-peptide levels (blood glucose $>7 \mathrm{mmol} / \mathrm{l}$ ) ranged from less than 0.03 to $0.28 \mathrm{nmol} / \mathrm{l}$ (median $0.05 \mathrm{nmol} / \mathrm{l}$ ). All were in good health and were non-obese (median BMI 22.3, range $18.8-25.9 \mathrm{~kg} / \mathrm{m}^{2}$ ) with normal hepatic, renal and thyroid function. All subjects were using combinations of short and intermediate acting insulins administered two or four times daily. (Insulin dose 0.8 to $1.5 \mathrm{U} / \mathrm{kg}$, median $1.0 \mathrm{U} / \mathrm{kg}$ ). The median $\mathrm{HbA}_{1}$ level was $13.5 \%$ (range $7.1-17.0 \%$; reference range 5.6 to $7.6 \%$ ). 


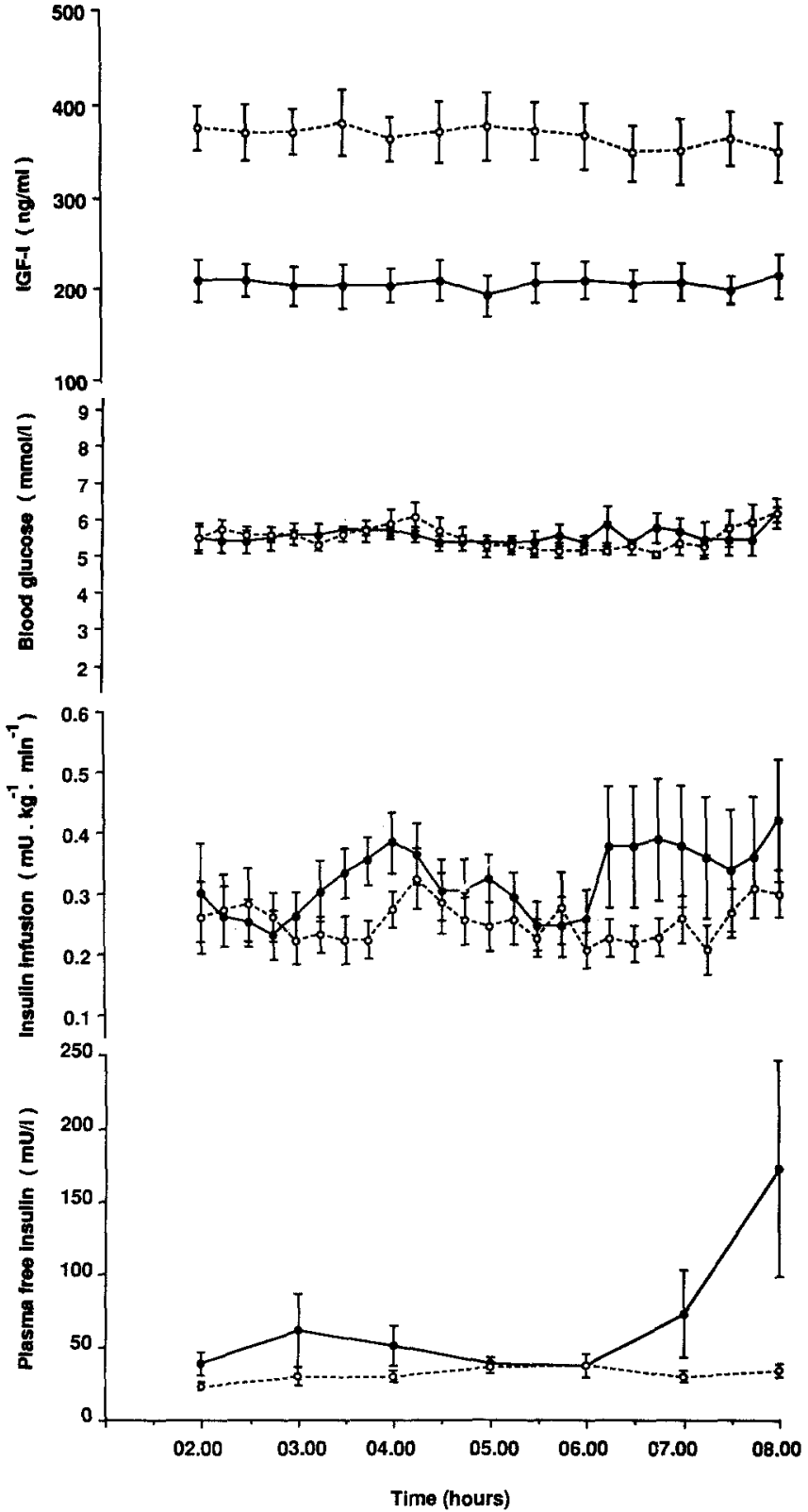

Fig. 1. Insulin-like growth factor I, blood glucose, insulin infusion rate and free insulin levels (mean \pm SEM) during the stable clamp between 02.00-08.00 hours after administration of placebo $(\bullet)$ and recombinant human insulin-like growth factor I $(O)$. One subject has been excluded from the analysis

The study protocol was approved by the Central Oxford Research Ethical Committee and informed consent was obtained from the subjects and their parents.

\section{Study design and procedures}

All intermediate acting insulin was withdrawn at least $36 \mathrm{~h}$ before admission and blood glucose concentrations controlled with regular injections of soluble insulin; the last dose being given at the time of the midday meal on the day of admission. The two study periods were separated by an interval of 1-2 weeks.

Subjects were admitted to hospital at 16.30 hours and cannulae were inserted into a distal forearm and an antecubital fossa vein.
Recombinant human IGF-I (rhIGF-I) in a dose of $40 \mu \mathrm{g} / \mathrm{kg}$ body weight or placebo was administered double blind at 18.00 hours (s. c. into the anterior aspect of the left thigh). After the evening meal at 18.00 hours, which was low in fibre and of a similar carbohydrate content on each of the two study periods, subjects fasted overnight. Basal blood samples were taken before the injection of the rhIGF I or placebo and thereafter at $15 \mathrm{~min}$ (glucose and GH), $30 \mathrm{~min}$ (IGFI) and $60 \mathrm{~min}$ (insulin, ketones and lactate) intervals.

Blood glucose control was achieved by a continuous insulin infusion with the rate designed to maintain a blood glucose of $5 \mathrm{mmol} / \mathrm{l}$ calculated by a computer program and a portable bedside Apple IIe computer from 15-min blood glucose measurements [9]. Continuous blood sampling was carried out through a continuously heparinized double lumen cannula inserted into the distal forearm. The forearm of the limb used for sampling was maintained in a heated box to "arterialize" the venous blood. Subjects relaxed in the supine position from early evening and went to sleep at similar times during both study periods.

\section{Assays}

Whole blood glucose was determined by a Yellow Springs Instruments analyser (Clandon Scientific Ltd, Farnborough, Hants., UK).

Samples for GH assay were centrifuged, separated and the plasma frozen at $-20^{\circ} \mathrm{C}$ until assay. Plasma GH concentrations were measured by immunoradiometric assay (NETRIA) as previously described [1]. For plasma free insulin $1.0 \mathrm{ml}$ of whole blood was added immediately to $0.6 \mathrm{ml}$ of ice-cold $25 \%$ polyethylene glycol (PEG mol. wt. 6000; Sigma Ltd, Poole, Dorset, UK). Samples were stored at $0^{\circ} \mathrm{C}$ then separated and centrifuged within $13 \mathrm{~h}$. The plasma was stored at $-20^{\circ} \mathrm{C}$ and assayed by double-antibody RIA (Guildhay Antisera Ltd, Guildford, Surrey, UK). Inter-assay coefficients of variation at 12.2 and $47.2 \mathrm{mU} / \mathrm{l}$ were $5.5 \%$ and $8.6 \%$, respectively. Plasma samples for IGF-I determination were acid-ethanol extracted and IGF-1 concentrations determined by RIA as described previously [8]. Samples for ketone and lactate were taken directly into ice-cold $10 \%$ perchloric acid and after separation were assayed by standard techniques [4].

\section{Statistical analysis}

A pulse detection program, Pulsar, was used to analyse GH profiles as in previous studies from our department [1]. Data are expressed as mean \pm SEM unless otherwise stated. Blood glucose and insulin infusion data were normally distributed. Log-transformation normalised the ketone and plasma free insulin data and, therefore, parametric statistical tests have been used. Analysis of variance (one and two-way ANOVA) were used to examine changes with time. The Pulsar parameters were analysed using Wilcoxon's matched pairs signed rank test.

\section{Results}

Of the nine subjects, four received rhIGF-I during the first study period. Mean plasma IGF-I concentrations rose from $223 \mathrm{ng} / \mathrm{ml}$ to a peak of $413 \mathrm{ng} / \mathrm{ml}, 5.5 \mathrm{~h}$ after the injection of rhIGF-I and then remained elevated throughout the night. (Overall mean values on rhIGF-I study night: $359 \pm 26 \mathrm{ng} / \mathrm{ml}$ vs placebo: $206 \pm 22 \mathrm{ng} / \mathrm{ml} ; p<0.001$; Fig. 1). No subject experienced side effects following the IGF-I administration.

Mean blood glucose concentrations were significantly lower after rhIGF-I administration between 23.30 and 00.30 hours $(4.55 \pm 0.04$ compared to $5.58 \pm 0.07 \mathrm{mmol} / \mathrm{l}$; 


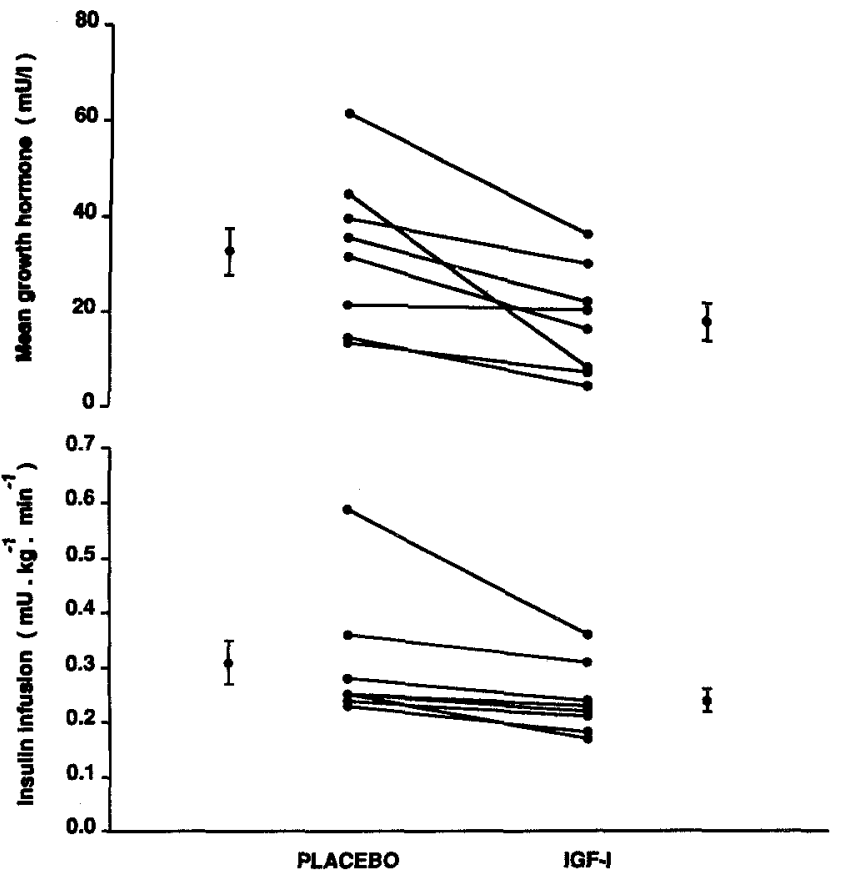

Fig. 2. Mean growth hormone levels (20.00-08.00 hours) and mean insulin infusion rate (02.00-08.00 hours) in the two groups, placebo and recombinant human insulin-like growth factor I (rhIGF-I). One subject has been excluded from the analysis

$p<0.05)$. The lowest mean blood glucose was observed at 23.30 hours after rhIGF-1 administration (4.49 \pm $0.34 \mathrm{mmol} / \mathrm{l}$ ) and at 00.15 hours after placebo (5.44 \pm $0.44 \mathrm{mmol} / \mathrm{l})$. However, there was no significant difference in the lowest blood glucose concentration reached in each subject when the two study periods were compared. No subject experienced hypoglycaemic symptoms on either night and in particular no subject experienced severe hypoglycaemic symptoms or an increase in the frequency of mild hypoglycaemia between or after the study periods. However, one individual was excluded from further analysis because blood glucose concentrations fell below $3.5 \mathrm{mmol} / 1$ on both study nights $(3.3 \mathrm{mmol} / 1$ after placebo and $2.5 \mathrm{mmol} / \mathrm{l}$ after rhIGF-I administration).

A stable blood glucose was reached by 02.00 hours in all subjects on both nights (Fig. 1; mean blood glucose concentrations $02.00-08.00$ hours were $5.62 \pm 0.13 \mathrm{mmol} / \mathrm{l}$ after placebo and $5.59 \pm 0.07 \mathrm{mmol} / \mathrm{l}$ after rhIGF-I). Analysis of the insulin infusion during the period 02.00 08.00 hours revealed a significant reduction in the insulin requirements to maintain euglycaemia in the group receiving rhIGF-I when compared to the control group $\left(0.25 \pm 0.02\right.$ vs $0.31 \pm 0.04 \mathrm{mU} \cdot \mathrm{kg}^{-1} \cdot \mathrm{min}^{-1} ; \quad p=0.03$; Figs. 1, 2). Insulin infusion rate correlated with plasma free insulin levels during this period on the placebo night $(r=0.33, p=0.01)$ and on the IGF-I night $(r=0.35$, $p=0.008)$. Mean plasma free insulin levels between 02.00-08.00 hours were also significantly reduced after rhIGF-I administration ( $31.9 \pm 2.7$ vs $67.9 \pm 16.0 \mathrm{mU} / \mathrm{l}$; $p=0.001$; Fig. 1 ) .

There was evidence of a change in GH concentrations within the first $6 \mathrm{~h}$ after rhIGF-I administration (mean GH levels $18.00-24.00$ hours $(10.7 \pm 1.4$ after rhIGF-I vs
$28.0 \pm 5.7 \mathrm{mU} / 1$ after placebo; $p=0.02$ ). Mean GH levels between 20.00 and 08.00 hours were also reduced after rhIGF-I when compared to placebo $(19.4 \pm 4.0$ vs $33.6 \pm 5.8 \mathrm{mU} / 1 ; p=0.01$; Fig. 2 ). The Pulsar program demonstrated a significant reduction in mean $\mathrm{GH}$ peak amplitude ( $36.7 \pm 6.8$ vs $57.3 \pm 8.1 \mathrm{mU} / \mathrm{l} ; p=0.01$ ), maximum GH concentration $(103.9 \pm 27.0$ vs $150.1 \pm 28.6$; $p=0.05)$ and in the mean calculated baseline GH concentration ( $4.0 \pm 1.2$ vs $8.1 \pm 2.5 \mathrm{mU} / 1 ; p=0.02)$ after rhIGF-I administration. No significant differences in the other Pulsar parameters were observed. Intermediate metabolite levels, B-hydroxybutyrate, acetoacetate and lactate were not significantly different on the two study nights.

\section{Discussion}

Mean serum IGF-I levels in our patients studied on the placebo night $(206 \pm 22 \mathrm{ng} / \mathrm{ml})$ were low compared to the normal range for adolescents in stage 4-5 puberty [8] and after rhIGF-I administration normal, but not high, levels were achieved. This led to a reduction in GH levels in all of the subjects studied. The change in GH profiles was characterised by a reduction in GH pulse amplitude and baseline concentrations whereas $\mathrm{GH}$ pulse frequency did not appear to be affected by rhIGF-I administration. These observations provide further evidence to support the hypothesis that it is the reduced IGF-I levels and reduced IGF bioactivity which lead to disordered feedback and elevated GH levels in adolescents with Type 1 diabetes [6].

The reduction in $\mathrm{GH}$ pulse amplitude after rhIGF-I administration was also associated with changes in insulin sensitivity. During the stable clamp period, overall mean insulin requirements for euglycaemia were reduced in all of the subjects studied. Furthermore, the oscillations in insulin requirements related to $\mathrm{GH}$ pulses in subjects with Type 1 diabetes [4], were abolished after rhIGF-I administration but were noted on the placebo night.

A reduction in $\mathrm{GH}$ concentrations was noted within the first $6 \mathrm{~h}$ after rhIGF-I administration and it could be argued that all of the changes in insulin sensitivity were a direct result of this change. However, it is known that in high doses rhIGF-I has direct insulin-like effects, although low doses such as those used in our study do not lead to symptoms of hypoglycaemia or affect fasting levels of insulin in normal subjects [10]. Any direct effect of rhIGF-I might have been expected during the first few hours following rhIGF-I administration before levels peaked at $5.5 \mathrm{~h}$. The mean blood glucose nadir was lower following rhIGF-I. However, when the blood glucose nadir on the two study nights was compared in individual subjects, there were no consistent differences. One subject did become hypoglycaemic but on both study nights and it is interesting to reflect that this subject had the lowest $\mathrm{HbA}_{1}$ and the best glycaemic control of the group studied. It is not possible to discount a direct effect of free IGF-I levels on glucose homeostasis particularly as IGF binding protein 3 levels tend to be low in adolescents with Type 1 diabetes. Further study of free IGF-I and binding protein levels may resolve this issue. 
We did not observe any consistent changes in intermediate metabolite concentrations although B-hydroxybutyrate and acetoacetate levels tended to be lower on the IGF-I night which would be consistent with the reduction in GH concentrations [6].

It is generally acknowledged that high $\mathrm{GH}$ levels and variable insulin requirements can lead to difficulties in achieving good glycaemic control in adolescents with Type 1 diabetes [6]. Although improved insulin delivery can correct at least some of the metabolic abnormalities [7], its implementation may not always be practical in this age group. Further studies of rhIGF-I administration in Type 1 diabetes should include detailed analysis of possible effects on diabetic complications but our preliminary data suggest it may have a useful role in suppressing $\mathrm{GH}$ levels and reducing insulin requirements.

Acknowledgements. We would like to acknowledge the help of Ms S.Strang, D. Harris and G. Davies for preparing the manuscript.

\section{References}

1. Edge JA, Dunger DB, Matthews DR, Gilbert JP, Smith CP (1990) Increased overnight growth hormone concentrations in diabetic compared with normal adolescents. J Clin Endocrinol Metab 71: 1356-1362

2. Batch JA, Werther GA (1992) Changes in growth hormone concentrations during puberty in adolescents with insulin dependent diabetes. Clin Endocrinol 36: 411-416

3. Fowelin J, Attvall S, von Schenck H, Smith U, Lager I (1991) Characterization of the insulin-antagonistic effect of growth hormone in man. Diabetologia 34: 500-506

4. Pal BR, Phillips PE, Matthews DR, Dunger DB (1992) Contrasting metabolic effects of continuous and pulsatile growth hor- mone administration in young adults with type 1 (insulin-dependent) diabetes mellitus. Diabetologia 35: 542-549

5. Perriello G, De Feo P, Torlone E et al. (1990) Nocturnal spikes of growth hormone secretion cause the dawn phenomenon in type 1 (insulin-dependent) diabetes mellitus by decreasing hepatic (and extrahepatic) sensitivity to insulin in the absence of insulin waning. Diabetologia 33: 52-59

6. Dunger DB, Edge JA, Pal R, Taylor AM, Holly JMP, Matthews DR (1991) Impact of increased growth hormone secretion on carbohydrate metabolism in adolescents with diabetes. Acta Paediatr Scand [Suppl] 377: 69--77

7. Amiel SA, Sherwin RS, Hintz RL, Gertner JM, Press CM, Tamborlane VW (1984) Effect of diabetes and its control on insulinlike growth factors in the young subject with type 1 diabetes. Diabetes 33: 1175-1179

8. Taylor AM, Dunger DB, Grant DB, Preece MA (1988) Somatomedin-C/IGF-1 measured by radioimmunoassay and somatomedin bioactivity in adolescents with insulin dependent diabetes compared with puberty matched controls. Diabetes Res 9:177-181

9. Matthews DR, Edge JR, Dunger DB (1990) An unbiased glucose clamp method using a variable insulin infusion: its application in diabetic adolescents. Diabetic Med 7:246-251

10. Wilton P, Sietnieks A, Gunnarsson R, Berger L, Grahnen A (1991) Pharmacokinetic profile of recombinant human insulinlike growth factor 1 subcutaneously in normal subjects. Acta Paediatr Scand [Suppl] 377: 111-114

Received: 22 January 1993

and in revised form: 2 March 1993

Dr D.B.Dunger

Department of Paediatrics

John Radcliffe Hospital

Oxford OX3 9DU

UK 